\title{
EL DERECHO HUMANO A SER PADRE/MADRE Y LA GESTACIÓN POR SUSTITUCIÓN
}

\author{
Elena GOÑI HUARTE \\ Departamento de Ciencias \\ Jurídicas y Políticas \\ Facultad de Ciencias Sociales \\ y de la Comunicación \\ Universidad Europea de Madrid \\ elena.goni@universidadeuropea.es
}

\section{INTRODUCCIÓN}

El problema social de la gestación por sustitución está planteando múltiples interrogantes a los que el Derecho debe dar respuesta. En este trabajo nos centraremos en uno de ellos: ¿existe el derecho humano a ser padre/ madre? Consideramos que es la cuestión que subyace en el fondo de toda esta problemática. Porque si existiera este derecho humano a la paternidad o maternidad, debería otorgarse por igual a todos los ciudadanos, independientemente del Estado del que formen parte.

Afrontaremos esta investigación jurídica partiendo de una visión general del derecho humano a la paternidad y maternidad para poder interpretar si es posible su ejercicio a través de la gestación por sustitución. Así, en primer lugar, analizaremos la normativa en materia de derechos humanos sobre el derecho a ser padre/madre. En segundo lugar, estudiaremos la protección que el Derecho internacional otorga a la dignidad del hijo para impedir su utilización como medio de transacción. En tercer lugar, examinaremos los únicos casos en los que el Tribunal Europeo de Derechos Humanos (en adelante, TEDH) se pronuncia sobre el fondo del problema de la gestación por sustitución: el caso Paradiso y Campanelli c. Italia y su Dictamen Consultivo de 10 de abril de 2019 solicitado por la Corte de Casación francesa. En cuarto lugar, compararemos la regulación española y la mexicana en esta materia. Por último, mostraremos nuestras conclusiones sobre este supuesto derecho humano a ser padre/madre y sobre la posibilidad de ejercerlo mediante la gestación por sustitución recurriendo a la adopción. 


\section{METODOLOGÍA}

La metodología será la propia de las ciencias jurídicas y sociales. Con una técnica de investigación cualitativa, se abordará el estudio del tema planteado mediante el empleo de las siguientes fuentes documentales: la normativa (internacional, española y mexicana) sobre la materia, la interpretación de la jurisprudencia del TEDH sobre la gestación por sustitución y las principales aportaciones de la doctrina jurídica al problema planteado.

\section{III. ¿EXISTE UN DERECHO HUMANO A SER PADRE/MADRE?}

Para responder a esta pregunta debemos partir de la Declaración Universal de Derechos Humanos de 10 de diciembre de 1948. El art. 16 de la Declaración establece: «Los hombres y las mujeres, a partir de la edad núbil, tienen derecho, sin restricción alguna por motivos de raza, nacionalidad o religión, a casarse y fundar una familia, y disfrutarán de iguales derechos en cuanto al matrimonio, durante el matrimonio y en caso de disolución del matrimonio».

También el art. 12 del Convenio para la Protección de los Derechos Humanos y de las Libertades Fundamentales de 4 de noviembre de 1950 señala: «A partir de la edad núbil, el hombre y la mujer tienen derecho a casarse y a fundar una familia según las leyes nacionales que rijan el ejercicio de este derecho».

A su vez, el art. 23.2 del Pacto Internacional de Derechos Civiles y Políticos de 16 de diciembre de 1966 declara: «Se reconoce el derecho del hombre y de la mujer a contraer matrimonio y a fundar una familia si tienen edad para ello».

Así, de esta regulación puede desprenderse que existe el derecho humano a fundar una familia, pero no queda claro si existe un derecho humano a ser padre/madre.

Ahora bien, el derecho humano a fundar una familia, como todo derecho, no es ilimitado, sino que, como señala Herrera, debe ser sopesado de conformidad con los demás derechos, principios e intereses en juego, como el interés superior del niño ${ }^{1}$. Porque solo el planteamiento «de un supuesto

${ }^{1}$ M. HerRera, «¿Existe un derecho al hijo? El lugar y los límites de las técnicas de reproducción humana asistida», Revista Jurídica de la Universidad Autónoma de Madrid, vol. 35 (2017), p. 76. 
"derecho al hijo" encierra, de por sí, una disyuntiva compleja y perversa a la vez, en la que se coloca a los hijos como "objetos" y no como verdaderos "sujetos" de derecho, como bien lo expone la Convención sobre los Derechos del Niño» ${ }^{2}$ y se regula a nivel nacional siguiendo las recomendaciones de la Observación General 14 del Comité de Derechos del Niño33.

En el caso de España, el art. 2 de la Ley Orgánica 1/1996, de 15 de enero, de Protección Jurídica del Menor, fue modificado por la Ley Orgánica 8/2015, de 22 de julio, de modificación del Sistema de Protección a la Infancia y a la Adolescencia, para incorporar (tal y como se señala en su Preámbulo) «tanto la jurisprudencia del Tribunal Supremo de los últimos años como los criterios de la Observación General 14, de 29 de mayo de 2013, del Comité de Naciones Unidas de Derechos del Niño, sobre el derecho del niño a que su interés superior sea una consideración primordial». Así, en la actualidad, dicho artículo establece: «Todo menor tiene derecho a que su interés superior sea valorado y considerado como primordial en todas las acciones y decisiones que le conciernan, tanto en el ámbito público como privado. En la aplicación de la presente ley y demás normas que le afecten, así como en las medidas concernientes a los menores que adopten las instituciones, públicas o privadas, los Tribunales o los órganos legislativos, primará el interés superior de los mismos sobre cualquier otro interés legítimo que pudiera concurrir».

A raíz de esta normativa podemos plantearnos la siguiente pregunta: ¿qué ocurre en la adopción? Creemos que la primacía del interés superior del niño sí se respeta en la adopción. Porque la adopción se configura como una vía o instrumento de integración familiar en atención del interés superior del niño, que es el principio que rige su regulación. Como advierte Ochoa Ruiz, la finalidad de la adopción consiste en poner remedio a una situación de abandono del niño buscándole la familia más adecuada para él, primando el interés superior del niño ${ }^{4}$. Sin embargo, como señala Herrera, las Técnicas de Reproducción Humana Asistida (en adelante, TRHA) también «constituyen un modo o vía para alcanzar o ver satisfecho este derecho humano: el derecho a fundar o formar una familia» ${ }^{5}$, pero ¿respetan también la supremacía del interés superior del niño?

${ }^{2}$ Ibid., pp. 74-75.

3 https://www2.obchr.org/English/bodies/crc/docs/GC/CRC.C.GC.14_sp.pdf.

${ }^{4}$ N. OchoA Ruiz, «La jurisprudencia del Tribunal Europeo de Derechos Humanos sobre gestación subrogada», en A. ROLDÁn MARTínez (dir.), La persona en el siglo XXI. Una visión desde el Derecho, Cizur Menor, Aranzadi Thomson Reuters, 2019, p. 78.

5 M. HerRerA, «¿Existe un derecho al hijo?...», op. cit., p. 73. 
En cualquiera de los casos, adopción o TRHA, coincidimos con Minyersky en que «no existe un derecho al niño, ya que reconocer el mismo sería violar todos los principios de la doctrina de protección integral que nos señala al niño como sujeto de derecho, una persona plena con iguales derechos, como tal, que los adultos». En el campo de las TRHA, la pregunta se podría reconducir a la siguiente: ¿existe un derecho a la procreación? ${ }^{6}$ ¿Podemos considerarlo un derecho subjetivo?

De Verda y Beamonte y Chaparro Matamoros definen el derecho subjetivo como «el concreto poder que las normas jurídicas conceden a una persona sobre los propios bienes de su personalidad (por ejemplo, su honor, intimidad o propia imagen) o sobre un objeto del mundo exterior (una cosa si estamos ante un derecho real, como sucede con el derecho de propiedad, o una conducta del deudor si estamos ante un derecho de crédito, como, por ejemplo, el pago de una renta mensual en el arrendamiento de vivienda)». El objeto de un derecho subjetivo es aquello sobre lo que recae el poder del titular y puede ser: una cosa, un comportamiento de una determinada persona o un bien o atributo inherente a la persona, que es lo que sucede con los derechos de la personalidad (por ejemplo, el derecho a la vida o al honor) ${ }^{7}$.

Consideramos que no puede existir un derecho subjetivo a la procreación, porque al final supondría convertir a la persona en objeto de Derecho (cosa, prestación o bien de la personalidad). El acto de procrear (de engendrar a otro $)^{8}$ no puede ser el objeto de un derecho subjetivo, ya que ello supone patrimonializar al otro (al hijo), que es persona, sujeto de derechos y no puede ser entonces objeto de derechos. Creemos, como el Tribunal Constitucional español (en adelante, TC), que más que un derecho a la procreación, lo que existe es una libertad de la persona: la libertad de procreación. Así, el TC en su Sentencia de 14 de julio de 1994 hace referencia a la «libertad de procreación que se deriva del libre desarrollo de la personalidad proclamado en el art. 10.1 CE», en el sentido de garantía negativa frente a la intromisión de terceros?.

Además, como advierte Sánchez Martínez ${ }^{10}$, el TEDH también ha considerado que se trata de una libertad. Este Tribunal entiende que el art. 8

${ }^{6}$ N. Minyersky, «¿Derecho al hijo/a?», en A. Kemelmajer de Carlucci (dir.), La familia en el nuevo Derecho, t. II, Santa Fe, Pontificia Universidad Javeriana, 2009, pp. 422-423.

7 J. R. de Verda y Beamonte y P. Chaparro Matamoros, Derecho Civil I (Derecho de la Persona), Valencia, Tirant lo Blanch, 2016, pp. 143-144.

${ }^{8}$ Según la RAE la definición de procrear: «Dicho de una persona o de un animal: engendrar un individuo de su misma especie».

9 STS 215/1994 de 14 julio (RTC 1994\215).

${ }_{10}$ M. O. SÁnCheZ MARTínEZ, «La gestación por sustitución: una consecuencia lógica de 
del Convenio para la Protección de los Derechos Humanos y de las Libertades Fundamentales, hecho en Roma el 4 de noviembre de 1950, reconoce el derecho al respeto de la vida privada y familiar, y que este derecho ampara dos libertades: por un lado, la libertad de ser padre o madre (o de no serlo) en sentido biológico, junto con el derecho al respeto de esta decisión ${ }^{11}$; y por otro, el derecho al respeto de la decisión de ser padre o madre recurriendo a la donación de gametos ${ }^{12}$.

También la Corte Interamericana de Derechos Humanos (en adelante, CIDH) en su Sentencia de 28 de noviembre de 2012 (caso Artavia Murillo y otros c. Costa Rica) señaló que «el derecho a la vida privada y la libertad reproductiva guarda relación con el derecho de acceder a la tecnología médica necesaria para ejercer ese derecho». Considera que «conforme al art. 29.b) de la Convención Americana, el alcance de los derechos a la vida privada, autonomía reproductiva y a fundar una familia, derivado de los arts. 11.2 y 17.2 de la Convención Americana, se extiende al derecho de toda persona a beneficiarse del progreso científico y de sus aplicaciones. Del derecho de acceso al más alto y efectivo progreso científico para el ejercicio de la autonomía reproductiva y la posibilidad de formar una familia se deriva el derecho a acceder a los mejores servicios de salud en técnicas de asistencia reproductiva, y, en consecuencia, la prohibición de restricciones desproporcionadas e innecesarias de iure o de facto para ejercer las decisiones reproductivas que correspondan en cada persona» ${ }^{13}$.

Por último, es preciso resaltar que para algunos autores la decisión o voluntad de ser padre o madre, más que una libertad, es simplemente un deseo. López Guzmán y Aparisi Miralles consideran que la gestación por sustitución cosifica al hijo, subordinándolo a los deseos de los adul$\operatorname{tos}^{14}$, y que, si bien el deseo de las parejas estériles debe ser escuchado por

la libertad reproductiva o un caso dramático de las reproducciones asistidas», Derechos y Libertades, vol. 44 (2021), p. 115.

${ }^{11}$ Caso Evans c. Reino Unido, núm. 6339/05, Sentencia de 10 de abril de 2007, párrs. 71 y 72 , disponible en https://budoc.echr.coe.int/eng\#\{\%22fulltext\%22:[\%22Evan s\%22], \%22documentcollectionid2\%22:[\%22GRANDCHAMBER\%22,\%22CHAMBER\% 22], \%22itemid\%22:[\%22001-80046\%22]\}.

12 Caso Dickson c. The United Kingdom, núm. 44362/04, Sentencia de 4 de diciembre de 2007, párr. 66, disponible en https://budoc.echr.coe.int/eng\#\{\%22fulltext\%22:[\%22Dick son \%22],\%22documentcollectionid2\%22:[\%22GRANDCHAMBER\%22,\%22CHAMBER \%22], \%22itemid\%22:[\%22001-83788\%22]\}.

${ }_{13}$ Caso Artavia Murillo y otros c. Costa Rica, Sentencia de 28 de noviembre de2012, párrs. 149 y 150, disponible en bttps://www.corteidh.or.cr/docs/casos/articulos/seriec_257_esp.pdf.

${ }^{14}$ J. López Guzmán y A. Aparisi Miralles, «Aproximación a la problemática ética y jurídica de la gestación por sustitución», Cuadernos de bioética, vol. 23 (2012), pp. 262-263. 
la sociedad, «no todos los deseos de los adultos deben ser considerados como derechos, máxime si ello implica lesiones a la dignidad y a los derechos de otros sujetos implicados, especialmente de las mujeres más vulnerables y de los hijos» ${ }^{15}$.

Es cierto que, como señala Herrera, visibilizar el deseo de los adultos de ser padres no es de por sí negativo. Incluso en la filiación por naturaleza o biológica, la mayoría de los hijos son una decisión —más o menos desarrollada - para su existencia. En esa misma línea, la adopción también es una decisión tomada por adultos ${ }^{16}$. Pero coincidimos con Arrechederra Aranzadi en que «el legítimo deseo de la paternidad no puede ser atendido si solo es posible a costa de la explotación de otra persona» ${ }^{17}$. El objetivo de una regulación de la gestación por sustitución «no puede efectuarse ni desde la perspectiva de los empresarios (o incluso del interés tributario del Estado) — que pretenden lucrarse del trabajo sexual o la necesidad de otros - ni desde la de los que pretenden convertir en derechos sus deseos» ${ }^{18}$.

En definitiva, entendemos que, en cualquier caso, libertad de procreación o deseo, ambos tienen límites: la dignidad de la mujer y del hijo. En este trabajo nos centraremos en la dignidad del hijo protegida por el art. 1 de la Declaración Universal de Derechos Humanos de 1948: «Todos los seres humanos nacen libres e iguales en dignidad y derechos y, dotados como están de razón y conciencia, deben comportarse fraternalmente los unos con los otros». La legalización de la gestación por sustitución puede ser contraria a dicho artículo porque supone la mercantilización de la persona cuando esta depende de una transacción. Además, coincidimos con López Guzmán y Aparisi Miralles en que el niño queda en una posición muy vulnerable, dado que su situación depende de las cláusulas establecidas en un contrato, porque la gestación por sustitución «especialmente cosifica al hijo, subordinándolo a los deseos de los adultos» ${ }^{19}$.

15 Ibid., p. 266. Concluyen que «en definitiva, el deseo de las parejas estériles debe ser escuchado por la sociedad. Sin embargo, no todos los deseos de los adultos deben ser considerados como derechos, máxime si ello implica lesiones a la dignidad y a los derechos de otros sujetos implicados, especialmente de las mujeres más vulnerables y los hijos».

${ }_{16}$ M. HeRRERA, «¿Existe un derecho al hijo?...», op. cit., p. 78.

17 L. I. ARECHEDERRA ARANZADI, No se alquila un vientre, se adquiere un bijo (la llamada gestación por sustitución), Cizur Menor, Aranzadi, 2018, disponible en https://proview.thomsonreuters.com/launchapp/title/aranz/monografias/205061589/v1.

18 bttps://elpais.com/elpais/2017/03/01/opinion/1488376776_471436.html.

19 J. López Guzmán, y A. Aparisi Miralles, «Aproximación a la problemática ética y jurídica...», op. cit., pp. 253 y 262-263. 
También la Sentencia de la Audiencia Provincial de Valencia de 23 de noviembre de 2011 señalaba las razones que llevaron al legislador español a prohibir, conforme al Derecho actualmente vigente en España, el contrato de gestación subrogada o por sustitución: «En concreto, se trata de los problemas que suscita esta figura en relación con principios tales como que la persona humana no puede ser objeto del comercio de los hombres o, lo que es lo mismo, que el niño no puede ser objeto de transacción, así la propia dignidad de la persona. Principios reflejados, además de en el art. 10.1 de la Constitución, en su art. 15, que reconoce el derecho a la integridad moral; el art. 39.2 de la misma norma fundamental, que proclama que los poderes públicos aseguran la protección integral de los hijos y de las madres cualquiera que sea su estado civil; el art. 1271 del Código Civil, que prescribe que pueden ser objeto de contrato todas las cosas que no están fuera del comercio de los hombres, y el art. 1275 del mismo cuerpo legal, que impide la producción de efectos a los contratos con causa ilícita [...]. Un contrato permitido según la ley de California, que tiene por objeto además una materia, como es la filiación y el estado civil, caracterizado por la indisponibilidad [...]. No se admite, en consecuencia, que, como dicen los apelantes, la filiación sea solo "una consecuencia última y periférica de dicho contrato", sino que constituye su causa para los comitentes y el objeto de la prestación de la madre gestante, conforme al art. 1274 del Código Civil español, y, por ello, un elemento esencial del mismo» ${ }^{20}$.

\section{DERECHO INTERNACIONAL QUE PROTEGE LA DIGNIDAD DEL HIJO}

Destacaremos la normativa más relevante en Derecho internacional que protege la dignidad del hijo para impedir su utilización como medio de transacción.

El art. 35 de la Convención sobre los Derechos del Niño, adoptada por la Asamblea General de las Naciones Unidas el 20 de noviembre de 1989, establece: «Los Estados Parte tomarán todas las medidas de carácter nacional, bilateral y multilateral que sean necesarias para impedir el secuestro, la venta o la trata de niños para cualquier fin o en cualquier forma».

El art. 4 del Convenio relativo a la protección del niño y a la cooperación en materia de adopción internacional, hecho en La Haya el 29 de

${ }^{20}$ SAP Valencia 826/2011, de 23 de noviembre (AC 2011\1561). 
mayo de 1993, señala: «Las adopciones consideradas por el Convenio solo pueden tener lugar cuando las autoridades competentes del Estado de origen [...] c) Se han asegurado de que [...] 3. Los consentimientos no se han obtenido mediante pago o compensación de clase alguna y que tales consentimientos no han sido revocados».

El art. 1 del Protocolo Facultativo de la Convención sobre los Derechos del Niño relativo a la venta de niños, la prostitución infantil y la utilización de niños en la pornografía, hecho en Nueva York el 25 de mayo de 2000, declara: «Los Estados Partes prohibirán la venta de niños, la prostitución infantil y la pornografía infantil, de conformidad con lo dispuesto en el presente Protocolo», y el art. 2 de dicho Protocolo regula lo siguiente: «A los efectos del presente Protocolo: a) Por venta de niños se entiende todo acto o transacción en virtud del cual un niño es transferido por una persona o grupo de personas a otra a cambio de remuneración o de cualquier otra retribución».

Respecto a la definición de venta de niños de este Protocolo, la opinión concordante de los jueces De Gaetano, Pinto de Albuquerque, Wojtyczek y Dedov en la Sentencia del TEDH de 24 de enero de 2017 (caso Paradiso y Campanelli c. Italia) considera que se trata de una «definición muy amplia de la venta de niños que se extiende a todas las transacciones, independientemente de su finalidad, y, por tanto, se aplica a los contratos celebrados con el fin de adquirir los derechos parentales. Los tratados internacionales antes mencionados reflejan una fuerte tendencia internacional hacia la limitación de la libertad contractual actual al prohibir cualquier tipo de contrato para la transferencia de niños o la transferencia de los derechos parentales a los niños, de lo que se deduce que resulta aplicable dicha definición a los contratos de gestación por sustitución [...]. Según el Comité de los Derechos del Niño, la gestación subrogada pagada, a falta de regulación, es la venta de niños (vid. las observaciones finales sobre el segundo informe periódico de los Estados Unidos de América presentado en virtud del art. 12 del Protocolo Facultativo de la Convención sobre los Derechos del Niño, sobre la venta de niños, la prostitución infantil y la pornografía infantil, CRC/C/OPSC/USA/CO/2 ${ }^{21}$;

${ }^{21}$ El Comité examinó el informe inicial de los Estados Unidos de América (CRC/C/ OPSC/USA/1) en su 1320. ${ }^{a}$ sesión ( $v i d$. CRC/C/SR.1320), celebrada el 22 de mayo de 2008, y en su 1342. ${ }^{2}$ sesión, celebrada el 6 de junio de 2008, y aprobó las siguientes observaciones finales: «A fin de fortalecer las medidas contra la venta de niños con fines de adopción, el Comité recomienda al Estado parte que aplique de manera apropiada y eficaz el Convenio de La Haya sobre la cooperación en materia de adopción internacional a fin de poner coto 
Observaciones finales sobre los informes periódicos tercero y cuarto de la India, CRC/C/IND/CO/3-4, 57-58) ${ }^{22}$.

En nuestra opinión, la gestación subrogada con fines comerciales, esté o no regulada, debe analizarse en virtud del art. 1 del Protocolo Facultativo de la Convención sobre los Derechos del Niño y, por tanto, es ilegal conforme al Derecho internacional. En términos más generales, creemos que la gestación subrogada, ya sea pagada o no, no es compatible con la dignidad humana. Constituye un tratamiento degradante no solo para el niño, sino también para la madre sustituta. [...] Tanto el hijo como la madre sustituta no son tratados como metas en sí mismos, sino como medios para satisfacer los deseos de los demás. Tal práctica no es compatible con los valores subyacentes al Convenio. La gestación subrogada es particularmente inaceptable si se paga a la madre sustituta. Lamentamos que el Tribunal de Justicia no haya adoptado una posición clara contra tales prácticas» ${ }^{23}$.

a los casos de venta de niños con fines de adopción; intensifique sus esfuerzos para prevenir y castigar todos los casos de venta de niños, en particular los que se realizan por Internet, independientemente del propósito de la venta». Vid. https://tbinternet.ohchr.org/_ layouts $/ 15 /$ treatybodyexternal/Download.aspx? symbolno $=C R C \% 2 F C \% 2 F O P S C \% 2 F U S A$ $\% 2 F C O \% 2 F 1$ ELang=en.

En su respuesta, Estados Unidos: «Según se indica en la sección V.J.5 del informe periódico de los Estados Unidos, tanto el Departamento de Estado como el Departamento de Seguridad Interior han publicado reglamentos que prohíben específicamente la compra de niños. En los reglamentos del Departamento de Seguridad Interior se establece con claridad que el consentimiento de la madre solo puede prestarse después del nacimiento del niño, de conformidad con lo estipulado en el párrafo c).4) del art. 4 del Convenio de La Haya, lo que reduce la posibilidad de ejercer influencia mediante el pago de gastos prenatales». Vid. bttps://www2.obchr.org/english/bodies/crc/docs/CRC.C.OPSC.USA.2_sp.pdf.

${ }_{22}$ Observaciones finales sobre los informes periódicos tercero y cuarto combinados de la India de 7 de julio de 2014: «El Comité acoge con satisfacción la publicación de las Directrices para la Adopción de Niños de 2011. Sin embargo, le preocupa que: no esté regulado adecuadamente y esté muy generalizado el uso comercial de la maternidad subrogada, lo que lleva a la venta de niños y a la violación de los derechos de los niños [...]. El Comité recomienda al Estado parte que garantice que el proyecto de ley sobre tecnología de reproducción asistida (reglamento) de 2013 o cualquier otra ley posterior contenga disposiciones que definan, regulen y vigilen los acuerdos de subrogación y tipifiquen como delito la venta de niños con fines de adopción ilegal, incluido el uso indebido de la maternidad subrogada. El Estado parte debe velar por que se tomen medidas contra todo el que participe en adopciones ilegales».Vid. bttps://tbinternet.ohchr.org/_layouts/15/treatybodyexternal/Download.asp $x$ ? symbolno $=C R C \% 2 f C \% 2 f I N D \% 2 f C O \% 2 f 3-4$.

${ }^{23}$ Caso Paradiso y Campanellic. Italia, Sentencia de 24 de enero de 2017 (JUR 2017/25806). 


\section{TEDH: CASO PARADISO Y CAMPANELLI C. ITALIA Y DICTAMEN CONSULTIVO DE 10 DE ABRIL DE 2019}

En el caso Paradiso y Campanelli c. Italia, la Sentencia del TEDH de 24 de enero de 2017 apoyó la postura de Italia contraria a la gestación por sustitución. En este caso, las autoridades italianas habían declarado en situación de desamparo a un menor que había pasado sus primeros ocho meses de vida con los comitentes, dos cónyuges italianos que habían accedido a la gestación por sustitución con gametos donados en Rusia.

El TEDH analiza esta cuestión desde la óptica del Convenio para la Protección de los Derechos Humanos y de las Libertades Fundamentales, hecho en Roma el 4 de noviembre de 1950, en concreto desde la posible vulneración de su art. 8: «Toda persona tiene derecho al respeto de su vida privada y familiar». Así, la Sentencia de 24 de enero de 2017 consideró que no existía vulneración del derecho a la vida familiar de los comitentes y que la injerencia en su vida privada se encontraba justificada. Consideró que en este caso no se cumplían los requisitos para considerar que existía una vida familiar de facto por «la ausencia de una conexión biológica entre el niño y los padres comitentes, la corta duración de la relación con el niño y la precariedad de la relación desde el punto de vista jurídico, y a pesar de la existencia de un proyecto de paternidad y la calidad de los lazos emocionales». Declaró que no existía vida familiar en este caso (párrs. 157 y 158) y concluyó señalando que «la Convención no consagra ningún derecho a convertirse en padre [...] Por consiguiente, el Tribunal de Justicia acepta que los órganos jurisdiccionales italianos, tras haber llegado a la conclusión de que el menor no sufriría un perjuicio grave o irreparable como consecuencia de la separación, han alcanzado un equilibrio adecuado entre los distintos intereses en juego al permanecer dentro de los límites de la amplia facultad discrecional de que disponen en el presente asunto» (párr. 215) ${ }^{24}$.

Hay que destacar la singularidad de esta sentencia porque, como advierte Ochoa Ruiz, «en otros casos de maternidad subrogada resueltos por el TEDH, el Tribunal entendió, sin embargo, que existía una vida familiar. La diferencia de fondo de estos casos con el presente parece estribar en el hecho de que en Paradiso y Campanelli no existía vínculo genético con los padres de intención». En el asunto D. y otros c. Bélgica ${ }^{25}$, el

\footnotetext{
${ }^{24}$ Ibid.

25 https://budoc.echr.coe.int/eng\#\{\%22appno\%22:[\%2229176/13\%22],\%22itemid\% 22:[\%22001-155182\%22]\}.
} 
TEDH consideró que sí existía vida familiar protegida por el art. 8 entre una pareja belga y un bebé nacido en Ucrania de una madre de alquiler, y ello a pesar de que la convivencia había durado tan solo dos meses. Las autoridades retiraron a la pareja provisionalmente la custodia, pero el niño les fue devuelto tras comprobarse que existía un vínculo genético con uno de los padres de intención. En los asuntos Mennesson c. Francia ${ }^{26}$ y Labassee c. Francia ${ }^{27}$ las autoridades francesas no retiraron en ningún momento a los padres de intención la custodia de los niños nacidos en Estados Unidos por gestación por sustitución, dado que en ambos casos el semen empleado procedía de los padres comitentes ${ }^{28}$.

También en el caso Foulón y Bouvet c. Francia los padres de intención eran padres genéticos. En este caso, la Sentencia del TEDH de 21 de octubre de $2016^{29}$ entendió que la negativa de Francia a reconocer una relación de filiación de los hijos con sus padres genéticos había producido una vulneración del derecho a la vida privada de los hijos (art. 8 del Convenio), relacionado con su derecho a su identidad y a la nacionalidad. De forma similar fue resuelto el caso Laborie c. Francia en la Sentencia del TEDH de 19 de enero de $2017^{30}$, donde también existía un vínculo genético entre el niño y el comitente varón.

Así, como establece Martínez de Aguirre, «vale la pena resaltar la importancia que el Tribunal concede a la existencia de relación biológica de filiación (presente en Mennesson, ausente en Paradiso) frente a planteamientos que parecen pretender rebajar dicha importancia, o incluso hacerla desaparecer, en relación con los vínculos legales de filiación» ${ }^{31}$.

De todos los casos analizados sí puede concluirse que, en materia de gestación por sustitución, para el TEDH existe vulneración de vida privada o familiar (art. 8 del Convenio) cuando no se reconoce la filiación con el padre o madre de intención que, a su vez, es padre o madre genético.

En definitiva, aunque en el caso Paradiso y Campanelli el TEDH apoyó la postura de Italia contraria a la gestación por sustitución, analizando otros pronunciamientos del TEDH no queda del todo clara su posi-

${ }^{26}$ Caso Mennesson c. Francia, Sentencia de 26 de junio de 2014 (JUR 2014-176908).

27 Caso Labassee c. Francia, Sentencia de 26 de junio de 2014 (JUR 2014-176905).

${ }^{28}$ N. OchoA RuIz, «Comentario a la Sentencia del Tribunal Europeo de Derechos Humanos de 24 de enero de 2017 en el asunto Paradiso y Campanelli c. Italia [GC]», Revista Aranzadi Doctrinal, vol. 9 (2017), BIB 2017 \13152.

${ }^{29}$ bttps://hudoc.echr.coe.int/fre\#\{\%22itemid\%22:[\%22001-164968\%22]\}.

30 https://budoc.echr.coe.int/eng\#\{\%22itemid\%22:[\%22001-170369\%22]\}.

31 C. Martínez de AguirRe, «El Tribunal Europeo de Derechos Humanos sobre maternidad subrogada», Escritos Jurídicos TFW, vol. 4 (2017), p. 3. 
ción sobre el problema en conjunto de este tipo de gestación. Sobre todo, después de su Dictamen Consultivo de 10 de abril de 2019 solicitado por la Corte francesa de Casación. En dicho Dictamen (Grande Chambre), el TEDH señala que una vez reconocida la paternidad legal del padre de intención que, a su vez, sea padre genético del niño, el derecho del niño al respeto de su vida privada en el sentido del art. 8 de la Convención requiere que la legislación nacional ofrezca la posibilidad de reconocer una relación legal con la madre intencional que, aunque no sea su madre biológi$\mathrm{ca}$, haya sido designada como madre legal en un certificado de nacimiento extranjero $^{32}$. Así, basándose en este Dictamen Consultivo, la Sentencia de 4 de octubre de 2019 de la Corte de Casación francesa falló declarando que la señora Mennesson (madre intencional) debía figurar en el Registro Civil como madre jurídica a pesar de no ser la madre biológica ${ }^{33}$.

Ahora bien, del Dictamen Consultivo del TEDH se desprende que, por lo que respecta a la madre de la intención, los Estados Parte no están obligados a optar por la transcripción de las partidas de nacimiento legalmente establecidas en el extranjero. Porque, como advierte De Verda y Beamonte, el Dictamen precisaba «que el establecimiento de la maternidad no tiene porqué realizarse a través de la inscripción en el Registro Civil nacional con base en el certificado de nacimiento extranjero, sino que se puede acudir a otras vías, como es la de la adopción, siempre que se garantice la efectividad y celeridad de las mismas, de acuerdo con el interés superior del niño» ${ }^{34}$.

Haciendo referencia a la adopción, se pronunciaba también la Sentencia de la Corte de Casación francesa de 4 de octubre de 2019: «La Primera Sala Civil del Tribunal de Casación, mediante cuatro Sentencias de 5 de julio de 2017 (1. ${ }^{a}$ Civ., 5 de julio de 2017, apela 15-28.597, Toro. 2017, I, 163, 16-16.901 y núm. 16-50.025, Toro. 2017, I, 164, núm. 16-16.455, Toro. 2017, yo, núm. 165) consideró que la adopción permite, si se cumplen las condiciones legales y si es en el mejor interés del niño, crear un vínculo de paternidad entre el niño y la madre de la intención, esposa del padre biológico. Según el Dictamen Consultivo, la adopción cumple, en

\footnotetext{
32 bttps://budoc.echr.coe.int/eng\#\{\%22itemid\%22:[\%22003-6380431-8364345\%22]\}.

33 https://www.courdecassation.fr/decision/5fca665048c4fb4f635a7452? search_api_fulltext $=$ $E s o r t=E i t e m s \_p e r \_p a g e=E j j u d i l i b r e \_c h a m b r e=E j u d i l i b r e \_t y p e=E j u d i l i b r e \_m a t i e r e=E j u d i l i b r e \_$ publication=Ejudilibre_solution $=\varepsilon \circ p=E d a t e \_d u=2019-10-04 \varepsilon d$ date_au=2019-10-04.

34 bttps://idibe.org/noticias-legales/dictamen-consultivo-del-tedh-maternidad-subrogadapracticada-pais-extranjero-donde-esta-practica-legal/.

bttps://idibe.org/tribuna/la-posicion-del-ts-espanol-respecto-la-maternidad-subrogadarealizada-extranjero-confirmada-dictamen-consultivo-del-tedh/.
} 
particular, los requisitos del art. 8 de la Convención sobre la Protección de los Derechos Humanos y las Libertades Fundamentales, siempre y cuando sus modalidades permitan una decisión rápida, a fin de evitar que el niño se mantenga en inseguridad jurídica sobre esta relación durante mucho tiempo, ya que el juez debe tener en cuenta la situación de vulnerabilidad de los niños mientras el procedimiento está pendiente». Sin embargo, la Corte de Casación descartó la alternativa de la adopción en el caso concreto, porque presuponía la iniciación de un nuevo procedimiento a iniciativa de la madre comitente y dado el tiempo transcurrido (las niñas habían nacido en el año 2000), ello tendría consecuencias manifiestamente excesivas para el derecho al respeto de la vida privada de las niñas ${ }^{35}$.

\section{REGULACIÓN DE LA GESTACIÓN POR SUSTITUCIÓN EN ESPAÑA Y MÉXICO}

En la actualidad, ambos países carecen de una regulación general que admita la gestación por sustitución.

En España, el art. 221.1 del Código Penal castiga a «los que, mediando compensación económica, entreguen a otra persona un hijo, descendiente o cualquier menor aunque no concurra relación de filiación o parentesco, eludiendo los procedimientos legales de la guarda, acogimiento o adopción, con la finalidad de establecer una relación análoga a la de filiación», con las penas de prisión de uno a cinco años y de inhabilitación especial para el ejercicio del derecho de la patria potestad, tutela, curatela o guarda por tiempo de cuatro a diez años.

Haciendo referencia expresa a la gestación por sustitución, la Ley 14/2006, de 26 de mayo, sobre técnicas de reproducción humana asistida española, en su art. 10 sanciona jurídicamente con la nulidad el contrato de gestación por sustitución: «Será nulo de pleno derecho el contrato por el que se convenga la gestación, con o sin precio, a cargo de una mujer que renuncia a la filiación materna a favor del contratante o de un tercero».

En México, el art. 169 del Código Penal para el Distrito Federal también establece: «Al que con el consentimiento de un ascendiente que ejerza la patria potestad o de quien tenga a su cargo la custodia de un menor,

\footnotetext{
35 bttps://www.courdecassation.fr/decision/5fca665048c4fb4f635a7452?search_api_

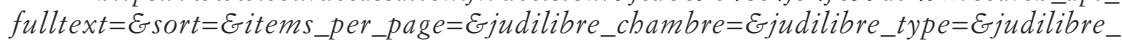
matiere $=\varepsilon j u$ dilibre_publication $=E j u d i l i b r e \_s o l u t i o n=E o p=E d a t e \_d u=2019-10-04 \varepsilon d a t e \_$ $a u=2019-10-04$.
} 
aunque esta no haya sido declarada, lo entregue ilegalmente a un tercero para su custodia definitiva a cambio de un beneficio económico, se le impondrán de dos a nueve años de prisión y de doscientos a quinientos días de multa».

Pero, a diferencia de España, en México cuatro Estados se refieren expresamente a la gestación por sustitución. En los demás Estados esta aún no se encuentra prevista en la ley.

Querétaro la prohíbe en el art. 400 de su Código Civil: «Las parejas adoptantes de embriones no podrán procurar la maternidad asistida o subrogada ni contratar el vientre de una tercera mujer para la gestación del embrión».

En el Estado Coahuila, como señalan Briseño Montes y Jurado Parres, existe cierta regulación con lagunas legales significativas. El art. 366 de Ley para la Familia de Coahuila de Zaragoza señala: «Se entiende por asistencia médica para la fecundación las prácticas clínicas y biológicas que permiten la concepción in vitro, la transferencia de embriones y la inseminación artificial, así como toda técnica de efecto equivalente que permita la fecundación fuera del proceso natural». De forma que deja al legislador la puerta abierta para que las disposiciones de este capítulo sean aplicadas a «toda técnica de efecto equivalente», entre las que podría entenderse la maternidad sustituta o subrogada, ya que se trata de un supuesto «de concepción embrionaria fuera del proceso natural» ${ }^{36}$.

Sin embargo, hay dos Estados que sí permiten la gestación por sustitución: Tabasco y Sinaloa. Nos centraremos en estos dos Estados donde está permitida.

En Tabasco, la gestación por sustitución está permitida para parejas heterosexuales y con carácter altruista ${ }^{37}$. El art. 380 bis.1 del Código Civil de Tabasco define así la gestación por contrato: «La gestación por contrato se efectuará a través de la práctica médica, mediante la cual una mujer gesta el producto fecundado por los padres contratantes cuando la madre pactante padece imposibilidad física o contraindicación médica para llevar a cabo la gestación en su útero». El art. 380 bis.2 admite dos formas de gestación por contrato:

36 C. Briseño Montes y H. JuRAdo Parres, «Gestación sustituta y subrogada en México, derecho humano no reconocido constitucionalmente», Revista Derechos Fundamentales a Debate, vol. 14 (2020), p. 39.

37 L. ÁlvareZ DE TOLEDO, «La regulación de la maternidad subrogada en los Estados de Tabasco y Sinaloa. Comparativa con la prohibición de maternidad por sustitución del Derecho español», Revista del Posgrado en Derecho de la UNAM, Nueva Epoca, vol. 8 (2018), p. 29. 
«I. Subrogada: implica que la gestante sea inseminada aportando sus propios óvulos y que, después del parto, entregue el recién nacido a la madre contratante mediante adopción plena.

II. Sustituta: implica que la gestante sea contratada exclusivamente para portar en su vientre un embrión obtenido por la fecundación de gametos de la pareja o persona contratante».

En el primer caso, el de gestación subrogada, en el que la gestante aporta su propio material genético, es preciso recurrir a la adopción para entregar al recién nacido a la madre contratante. Como señala Álvarez de Toledo, cuando la gestante tiene una vinculación genética con el nacido, entonces es reconocida como madre legal del niño y deberá renunciar a su maternidad en favor de la parte contratante. La transferencia de la maternidad debe operarse a través de la adopción ${ }^{38}$.

En cambio, en el segundo caso, en el de la madre gestante que no aporta su material genético, sino que es contratada exclusivamente para llevar en su vientre el embrión obtenido de los gametos de la pareja o persona contratante, se presume la maternidad de la madre contratante o intencional, ya que la aportación de su propio material genético implica su aceptación. Así, el art. 92 del Código Civil de Tabasco señala ${ }^{39}:$ :En el caso de los hijos nacidos como resultado de la participación de una madre gestante sustituta, se presumirá la maternidad de la madre contratante que la presenta, ya que este hecho implica su aceptación. En los casos en los que participe una madre subrogada, deberá estarse a lo ordenado para la adopción plena». Respecto del padre, operan las presunciones de paternidad del marido (art. 324) o de concubinato (art. 340).

En el Estado de Sinaloa la gestación por sustitución se permite para parejas heterosexuales. Sin embargo, a diferencia de Tabasco, se admite la gestación por sustitución pactada con compensación económica ${ }^{40}$. El art. 283 del Código Familiar del Estado de Sinaloa establece: «La maternidad subrogada se efectúa a través de la práctica médica mediante la cual

38 Ibid., p. 31.

39 Art. 92 del Código Civil: «Se entiende por madre gestante sustituta, la mujer que lleva el embarazo a término y proporciona el componente para la gestación, mas no el componente genético. Por el contrario, la madre subrogada provee ambos: el material genético y el gestante para la reproducción. Se considera madre contratante a la mujer que convenga en utilizar los servicios de la madre gestante sustituta o de la madre subrogada, según sea el caso».

${ }^{40}$ L. Álvarez DE TOLEDO, «La regulación de la maternidad subrogada en los Estados...», op. cit., p. 32. 
una mujer gesta el producto fecundado por un hombre y una mujer cuando la mujer padece imposibilidad física o contraindicación médica para llevar a cabo la gestación en su útero y es subrogada por una mujer gestante que lleva en su útero el embrión de los padres subrogados, cuya relación concluye con el nacimiento». Como modalidades de la maternidad de sustitución el art. 284 del Código Familiar regula las siguientes:

«- Subrogación total: implica que la mujer gestante sea inseminada aportando sus propios óvulos y que después de la gestación y el parto entregue el hijo a la pareja o persona contratante.

- Subrogación parcial: es la que se da cuando la gestadora es contratada exclusivamente para portar en su vientre un embrión fecundado in vitro que le ha sido trasplantado, pero que proviene de la unión de espermatozoide y óvulo de la pareja o persona contratante.

- Subrogación onerosa: es la que se da cuando una mujer acepta embarazarse en lugar de otra tal y como si se tratase de un servicio, por el cual se paga una cantidad cierta y determinada, además de los gastos de la gestación.

- Subrogación altruista: es la que se da cuando una mujer acepta gestar por cuenta de otra de manera gratuita».

\section{CONCLUSIONES}

El problema actual de la gestación por sustitución ha puesto de manifiesto que lo que subyace en el fondo es la reivindicación social de un «derecho a ser padre o madre». Dicho de otra manera, en el fondo está presente la reivindicación de un «derecho al hijo», la idea de que una libertad o un deseo puede convertirse en un derecho subjetivo. Así se refleja en los efectos que produce la gestación subrogada sobre el niño: se le cosifica, pues se convierte en la contraprestación pactada y su identidad también es pactada por los adultos al decidir quiénes han de ser sus padres. Todo esto es coherente con la nueva tendencia que puede vislumbrarse en los sistemas jurídicos occidentales: el subjetivismo en el Derecho.

Falta una visión de conjunto en el Derecho internacional sobre el problema de la gestación por sustitución. Esto es debido a que no existe un derecho humano a ser padre/madre ni un derecho al hijo. Tal y como señala el TEDH (caso Paradiso y Campanelli c. Italia), en el Convenio para la Protección de los Derechos Humanos y de las Libertades Fundamentales 
de 1950 no está reconocido un derecho a ser padre/madre. Lo que existe es un derecho humano a fundar una familia.

En España, el contrato de gestación por sustitución está sancionado jurídicamente con la nulidad. A diferencia de España, en México se admite legalmente en dos Estados: Tabasco y Sinaloa. Destacamos la regulación de Tabasco, donde se regula la necesidad de acudir al procedimiento de la adopción después del parto cuando no exista vínculo genético entre el hijo y la madre contratante, en concreto, cuando la mujer gestante fue quien aportó sus propios óvulos.

Aunque en el caso Paradiso y Campanelli el TEDH apoyó la postura de Italia contraria a la gestación por sustitución, analizando otros pronunciamientos de este Tribunal no queda clara su posición al respecto. Sobre todo, después de su Dictamen Consultivo de 10 de abril de 2019 solicitado por la Corte de Casación francesa. En dicho Dictamen, el TEDH señala que, reconocida la paternidad legal del padre de intención, que, a su vez, es padre genético del niño, el derecho del niño al respeto de la vida privada en el sentido del art. 8 del Convenio para la Protección de los Derechos Humanos y de las Libertades Fundamentales requiere que la legislación nacional ofrezca la posibilidad de reconocer una relación legal con la madre intencional. En este Dictamen, el TEDH pone el foco de atención en el derecho a la vida privada del niño protegido en el art. 8 del Convenio. Sin embargo, hay que resaltar que no exige que dicho reconocimiento se realice mediante la inscripción en el Registro, pudiéndose utilizar otro medio, como la adopción del niño por parte de la madre, siempre que el procedimiento establecido por la ley nacional garantice que se pueda implementar de manera rápida y efectiva.

En definitiva, consideramos que cuando no exista un vínculo genético entre la parte contratante (padre/madre intencional o ambos) y el hijo nacido mediante la gestación por sustitución, debería acudirse a la adopción para establecer el vínculo de filiación entre ellos y el hijo. Pero a diferencia de Tabasco, que regula esta vía de la adopción cuando no exista vínculo genético entre el hijo y la madre contratante (porque la mujer gestante fue quien aportó sus propios óvulos), consideramos que debe extenderse la solución de la adopción a todos los casos donde no exista vínculo genético entre los contratantes y el hijo nacido de la gestación por sustitución (con independencia del origen de los gametos) por varias razones:

En primer lugar, es la solución que mejor respeta la dignidad del niño, que deja de ser objeto de transacción en virtud de contrato para ser sujeto de derechos protegido mediante el procedimiento de adopción. Creemos 
que es la solución que mejor respeta el art. 1 de la Declaración Universal de Derechos Humanos de 1948: «Todos los seres humanos nacen libres e iguales en dignidad y derechos y, dotados como están de razón y conciencia, deben comportarse fraternalmente los unos con los otros».

En segundo lugar, es la solución más acorde con la doctrina del TEDH establecida en el caso Paradiso Campanelli c. Italia, donde declaró que no pueden los contratantes sin vinculación genética con el niño entender vulnerado su derecho a la vida privada y familiar.

En tercer lugar, también es coherente con el Dictamen Consultivo de 10 de abril de 2019 del TEDH. En él se establece que el derecho del niño al respeto de su vida privada requiere que la legislación nacional ofrezca la posibilidad de reconocer una relación legal con la madre intencional. Añade que dicha relación legal puede obtenerse a través de otras vías distintas a la inscripción de la certificación extrajera, como es la vía de la adopción, siempre que se garantice la efectividad y celeridad de las medidas de acuerdo con el interés superior del niño.

En cuarto lugar, porque poniendo el foco de atención en el derecho a la vida privada y familiar del niño, y no en la vida privada y familiar de los adultos, la adopción permite valorar y considerar de forma primordial su interés superior con la finalidad de conseguir su integración familiar. Ahora bien, también creemos que para conseguir proteger en la práctica el interés superior del niño y para que se garantice el respeto a su vida privada y familiar es necesario agilizar los trámites del procedimiento de adopción. 